\title{
PENGARUH KUALITAS PELAYANAN TERHADAP LOYALITAS PADA RATU HOTEL (EX. QUEEN HOTEL) DENPASAR DENGAN KEPUASAN PELANGGAN SEBAGAI INTERVENING
}

\author{
Komang Ary Pratiwi ${ }^{1}$, I Wayan Suartina ${ }^{2}$, Dewa Nyoman Benni Kusyana ${ }^{3}$, Ida \\ Ayu Made Sasmita Dewi 4 \\ 1,2,3,4 Jurusan Manajemen, Universitas Hindu Indonesia, Denpasar \\ e-mail : arypratiwikm@gmail.com , wynsuartina@gmail.com, benni.unhi@gmail.com , \\ dayusasmitaunhi@gmail.com
}

\begin{abstract}
Abstrak
Bisnis hotel adalah salah satu industri yang mengalami perkembangan paling cepat di wilayah Denpasar-Bali. Banyaknya pesaing menyebabkan pentingnya mendapatkan pelanggan setia ke arah hotel. Loyalitas dapat dipengaruhi oleh kualitas layanan dan kepuasan pelanggan saat menginap di hotel. Penelitian ini bertujuan untuk mengetahui pengaruh kualitas layanan, kepuasan pelanggan terhadap loyalitas.

Alat analisis data pada penelitian ini adalah Structural Equation Modeling (SEM) untuk mengetahui pengaruh antar variabel. Hasil penelitian ini menunjukkan bahwa kualitas layanan memiliki pengaruh positif signifikan terhadap kepuasan pelanggan, kepuasan pelanggan memiliki pengaruh positif signifikan terhadap loyalitas, kualitas layanan memiliki pengaruh positif signifikan terhadap loyalitas, kualitas layanan memiliki pengaruh positif signifikan terhadap loyalitas dengan kepuasan pelanggan sebagai variabel intervening.

Implikasi manajerial dari hasil penelitian adalah bahwa manajemen Hotel Ratu harus difokuskan pada kualitas layanan hotel yang terdiri dari faktor bukti fisik, kompetensi, kekuatan persepsi, garansi, dan empati untuk mencapai kepuasan dan kesetiaan pelanggan yang menginap di Hotel tersebut.
\end{abstract}

Kata kunci: Kualitas Layanan, Kepuasan Pelanggan, Loyalitas

Abstract
The hotel business is one of the fastest growing industries in the Denpasar-Bali region. The number of competitors causes the importance of getting loyal customers towards the hotel. Loyalty can be influenced by service quality and customer satisfaction when staying at a hotel. This study aims to determine the effect of service quality, customer satisfaction on loyalty.

Data analysis tool in this study is Structural Equation Modeling (SEM) to determine the effect between variables. The results of this study indicate that service quality has a significant positive effect on customer satisfaction, customer satisfaction has a significant positive effect on loyalty, service quality has a significant positive effect on loyalty, service quality has a significant positive effect on loyalty with customer satisfaction as an intervening variable.

The managerial implication of the research results is that the management of the Ratu Hotel must be focused on the quality of hotel services consisting of physical evidence, competence, strength of perception, guarantee, and empathy to achieve the satisfaction and loyalty of customers who stay at the Hotel.

Keywords : Service Quality, Customer Satisfaction, Loyalty

\section{Pendahuluan}

Bali merupakan salah satu daerah di Indonesia dan menjadi daerah tujuan wisata dunia yang terkenal di mancanegara, dengan luas wilayahnya yaitu $5.632,86 \mathrm{~km}^{2}$ atau sebesar 0,29 persen dari luas kepulauan Indonesia. Selain itu, Bali adalah sebuah branded tourist object yang sudah masuk dalam benak wisatawan selaku konsumen. Pada tahun 1970-an pariwisata Bali mengalami masa booming, jasa perhotelan nampak mengalami perkembangan dengan pesat. Hotel Internasional Pertama yang diresmikan di Bali adalah Hotel Bali Beach yang berlokasi di wilayah Sanur, Denpasar-Bali.

Pada Tahun 2019, jasa perhotelan di Bali khususnya Denpasar mengalami kemajuan pesat, banyaknya hotel-hotel baru yang didirikan lengkap dengan fasilitas-fasilitasnya terutama di daerah Denpasar. Hal ini menyebabkan persaingan semakin ketat dalam meraih pelanggan, memenangkan persaingan dan dalam meningkatkan profitabilitas perusahaan. 
Ratu Hotel (Ex.Queen Hotel) merupakan hotel yang telah lama berdiri di daerah Denpasar Barat. Hotel-hotel yang berada di daerah Denpasar Barat hingga saat ini mencapai 52 hotel (Dinas Pariwisata Propinsi Bali, 2019). Hal ini menyebabkan tingkat perkembangan jumlah wisatawan selaku konsumen yang menginap di Ratu Hotel (Ex.Queen Hotel) mengalami ketidakstabilan dan bahkan terjadi penurunan. Berdasarkan fenomena gap tersebut, maka peneliti tertarik melakukan penelitian pada Ratu Hotel (Ex.Queen Hotel) di Denpasar-Bali.

Salah satu faktor penting untuk meraih konsumen selaku pelanggan dan mendatangkan profitabilitas perusahaan semaksimal mungkin adalah faktor kualitas pelayanan. Adanya kualitas pelayanan yang baik menimbulkan kepuasan tersendiri bagi pelanggan, yang pada akhirnya berpengaruh terhadap loyalitas pelanggan. Pada penelitian Omoregie et al (2018) dinyatakan bahwa loyalitas pelanggan dapat dipengaruhi oleh kualitas pelayanan dan kepuasan pelanggan. Hal ini juga didukung oleh hasil penelitian Carranza et al (2018) yang menyatakan bahwa kualitas yang baik berpengaruh terhadap peningkatan kepuasan dan loyalitas konsumen. Namun di sisi lain, masih terdapat beberapa hasil penelitian menyatakan hal yang berbeda yaitu hasil penelitian Chandra et al (2018) yaitu tidak ada pengaruh positif atau signifikan kualitas layanan terhadap loyalitas dan kualitas pelayanan tidak menjamin adanya kepuasan pelanggan. Berdasarkan Fenomena gap dan Research gap tersebut, peneliti ingin melakukan penelitian kembali berkaitan dengan kualitas pelayanan, kepuasan pelanggan, dan loyalitas pelanggan pada Ratu Hotel (Ex. Queen Hotel) di Denpasar-Bali.Berdasarkan uraian pada latar belakang masalah, dapat dirumuskan masalah penelitian sebagai berikut: 1) Apakah kualitas pelayanan berpengaruh positif dan signifikan terhadap kepuasan pelanggan? 2) Apakah kepuasan pelanggan berpengaruh positif dan signifikan terhadap loyalitas pelanggan? 3) Apakah kualitas pelayanan berpengaruh positif dan signifikan terhadap loyalitas pelanggan ? 4) Apakah kualitas pelayanan berpengaruh positif dan signifikan terhadap loyalitas pelanggan dengan kepuasan pelanggan sebagai variabel intervening?

Berdasarkan uraian pada latar belakang masalah dan rumusan masalah, dapat ditentukan tujuan dari penelitian ini adalah untuk mengetahui dan menguji :

1. Pengaruh kualitas pelayanan terhadap kepuasan pelanggan

2. Pengaruh kepuasan pelanggan terhadap loyalitas pelanggan

3. Pengaruh kualitas pelayanan terhadap loyalitas pelanggan

4. Pengaruh kualitas pelayanan terhadap loyalitas pelanggan dengan kepuasan pelanggan sebagai variabel intervening

Chandra et al (2018) mengemukakan definisi kualitas sebagai kesesuaian dengan spesifikasi pelanggan. Ide dasarnya adalah kualitas bukanlah memenuhi sejumlah kriteria yang ditetapkan perusahaan, sebaliknya kualitas adalah memenuhi kriteria yang ditetapkan pelanggan. Kunci untuk mencapai kualitas pelayanan yang baik adalah mengetahui siapa yang menjadi pelanggan dan apa yang mereka inginkan. Maka dari itu pengertian kualitas pelayanan yaitu berpusat pada upaya pemenuhan kebutuhan dan keinginan pelanggan serta ketepatan penyampaiannya untuk mengimbangi harapan pelanggan. Kualitas pelayanan merupakan perbedaan antara pengharapan pelanggan mengenai sebuah pelayanan yang akan diterima dan persepsi dari pelayanan yang diterima Chandra et al (2018).

Pengaruh kualitas terhadap loyalitas juga telah dibuktikan oleh hasil penelitian Sivapalan et al (2017) yang menyimpulkan bahwa peningkatan kualitas jasa akan memberikan dampak yang baik untuk meningkatkan loyalitas. Namun berbeda dengan hasil penelitian Chandra et al (2018) yang menyatakan bahwa kualitas tidak mempunyai pengaruh langsung dengan loyalitas. Oleh sebab itu memahami kebutuhan pelanggan sangat penting bagi perusahaan jasa yang bergerak dalam bidang perhotelan seperti Ratu Hotel (Ex.Queen Hotel) Denpasar. Dengan memahami kebutuhan pelanggan maka perusahaan dapat memberikan layanan yang berkualitas agar dapat bersaing dalam usaha perhotelan yang semakin kompetitif.

Khesavars et al (2018) mengemukakan bahwa terdapat lima dimensi dalam mengukur kualitas pelayanan, yaitu :

1. Bukti fisik (tangibles)

Yaitu : meliputi fasilitas fisik, peralatan dan penampilan karyawan 


\section{Reliabilitas (reliability)}

Yaitu : kemampuan memberikan pelayanan yang dijanjikan dengan segera, akurat, dan memuaskan

3. Daya tanggap (responsiveness)

Yaitu : keinginan para staf untuk membantu para pelanggan dan memberikan layanan dengan tanggap

4. Jaminan (assurance)

Yaitu : mencakup pengetahuan, kesopanan, dan sifat dapat dipercaya yang dimiliki para staf, sistem keamanan yang baik, bebas dari bahaya, risiko atau keragu-raguan

5. Empati (empathy)

Yaitu : kepedulian dan perhatian individual meliputi komunikasi yang baik, perhatian pribadi, dan pemahaman atas kebutuhan individual para pelanggan.

Semakin tajamnya persaingan dalam dunia usaha di zaman globalisasi seperti sekarang ini, maka adanya pelanggan merupakan hal yang sangat penting. Karena kunci keberhasilan perusahaan sebenarnya sangat tergantung kepada suksesnya perusahaan dalam memuaskan kebutuhan konsumen selaku pelanggannya. Pengertian kepuasan pelanggan menurut Khesavars et al (2018) adalah nilai yang dirasakan dan diperoleh dari seorang konsumen yang membeli sebuah produk tertentu. Kepuasan itu sendiri merupakan perasaan senang atau kecewa seseorang yang muncul setelah membandingkan kinerja (hasil) produk terhadap kinerja (hasil) yang diharapkan. Jika kinerja berada di bawah harapan, pelanggan tidak puas. Jika kinerja memenuhi harapan, pelanggan puas. Jika kinerja melebihi harapan, pelanggan amat puas atau senang. Kata "kepuasan atau satisfaction' berasal dari Bahasa Latin "satis" (artinya cukup baik, memadai) dan "facio" (melakukan atau membuat). Secara sederhana kepuasan diartikan sebagai "upaya pemenuhan sesuatu' atau 'membuat sesuatu memadai' Chandra et al (2018).

Keberhasilan sebuah industri jasa dalam merealisasikan tujuannya ditentukan pula oleh kemampuan perusahaan bersangkutan dalam mengidentifikasi kebutuhan dan keinginan pasar sasarannya, Memberikan kepuasan yang diharapkan secara lebih efektif dan efisien daripada para pesaingnya.

Pelanggan yang sedikit puas atau netral dapat direbut oleh pesaing, dan pelanggan yang senang akan tetap loyal walaupun ada tawaran yang menarik dari pesaing. Kepuasan pelanggan memainkan peran yang sangat penting dalam bisnis jasa yang sangat bersaing, karena terdapat perbedaan yang sangat besar dalam loyalitas antara pelanggan yang sekadar puas dan yang benar-benar puas. Terdapat 4 (empat) metode yang banyak dipergunakan dalam mengukur kepuasan pelanggan yang terdiri atas :

1. Sistem Keluhan dan Saran

Sistem ini memberikan kesempatan yang seluas-luasnya kepada pelanggan untuk menyampaikan saran, kritik, pendapat, dan keluhan mereka. Media yang digunakan bisa berupa kotak saran yang diletakkan di tempat-tempat strategis (yang mudah diakses atau sering dilalui pelanggan), kartu komentar (yang bisa diisi langsung maupun yang dikirim via pos kepada perusahaan), saluran telepon khusus bebas pulsa, website, dan lain-lain.

2. Ghost Shopping

Salah satu metode untuk memperoleh gambaran mengenai kepuasan pelanggan adalah dengan mempekerjakan beberapa orang ghost shoppers untuk berperan sebagai pelanggan potensial jasa perusahaan dan pesaing. Mereka diminta melaporkan berbagai temuan penting berdasarkan pengalamannya mengenai kekuatan dan kelemahan jasa perusahaan dibandingkan para pesaing. Selain itu, para ghost shoppers juga dapat mengobservasi cara perusahaan dan pesaingnya melayani permintaan spesifik pelanggan, menjawab pertanyaan pelanggan, dan menangani setiap masalah/keluhan pelanggan.

3. Lost Customer Analysis

yaitu menghubungi para pelanggan yang telah berhenti membeli atau yang telah beralih pemasok agar dapat memahami mengapa hal itu terjadi untuk mengambil langkah perbaikan, juga termasuk pemantauan customer loss rate yang menunjukkan kegagalan perusahaan dalam memuaskan pelanggannya. 


\section{Survei kepuasan pelanggan}

Survei kepuasan pelanggan dapat dilakukan dengan pemberian kuesioner (bisa dikirim melalui pos atau dibagikan pada saat pelanggan berbelanja atau pada saat menikmati pelayanan yang diberikan), lewat telepon, email, fax atau dengan wawancara langsung. Tujuan mengadakan survei ini adalah untuk memperoleh respon atau tanggapan dan umpan balik langsung dari pelanggan dan juga memberikan sinyal positif bahwa perusahaan menaruh perhatian terhadap mereka.

Loyalitas konsumen selaku pelanggan merupakan tujuan inti yang diupayakan pemasar. Hal ini dikarenakan loyalitas sesuai dengan yang diharapkan, dapat dipastikan perusahaan akan meraih keuntungan. Loyalitas pelanggan sangat penting untuk dikenali pemasar dalam rangka menentukan strategi yang diperlukan untuk meraih, memperluas dan mempertahankan pasar serta menjaga eksistensi perusahaan. Bagi perusahaan manapun adalah mahal untuk mendapatkan pelanggan baru. Sebaliknya, relatif tidak mahal untuk memelihara pelanggan yang sudah ada, terutama jika para pelanggan tersebut sudah puas atau bahkan menyukai barang atau jasa yang diberikan sehingga konsumen selaku pelanggan menjadi lebih loyal dalam melakukan pembelian dan menggunakan barang atau jasa yang ditawarkan oleh pihak perusahaan.

Sedangkan pengertian loyalitas pelanggan menurut Omoregie et al (2018), adalah keputusan pelanggan untuk secara suka rela terus berlangganan dengan perusahaan tertentu dalam jangka waktu yang lama.Tidak ada jaminan bahwa bila loyalitas terwujud lantas bisa langgeng dengan sendirinya. Pada prinsipnya, perusahaan harus selalu aktif mencari berbagai inovasi dan terobosan dalam merespons setiap perubahan menyangkut faktor 3C (Customers, Company, dan Competitors).

Efek loyalitas bagi perusahaan adalah memberikan sumber pendapatan terus menerus dalam kurun waktu bertahun-tahun. Loyalitas dapat dibagi menjadi 3 (tiga) kategori yaitu :

1. Repurchase Intention, yaitu keinginan atau niat yang kuat dari konsumen untuk membeli kembali produk (barang dan jasa) tertentu

2. Advocacy Intentions, yaitu keinginan atau niat dari konsumen selaku pelanggan yang menganjurkan pada calon pelanggan lainnya untuk menggunakan produk yang disarankan oleh konsumen bersangkutan

3. Paymore, yaitu kesediaan untuk membayar lebih

Menurut Khesavars et al (2018), pengertian loyalitas pelanggan adalah ekspresi perilaku yang dimaksudkan berhubungan dengan produk atau pelayanan pada perusahaan. Aspek perilaku dari loyalitas pelanggan mewakili pembelian berulang aktual dari produk atau pelayanan yang memasukkan pembelian produk atau pelayanan yang lebih dan berbeda dari perusahaan yang sama, merekomendasikan perusahaan kepada orang lain, dan pelanggan bersedia membayar lebih atas produk tambahan yang disediakan penyedia jasa, yang mencerminkan kemungkinan pilihan jangka panjang dari merek atau produk tersebut.

Khesavars et al (2018) menyatakan semakin tinggi tingkat kualitas pelayanan mengakibatkan semakin tingginya kepuasan pelanggan dan mendukung harga jasa yang lebih tinggi. Kualitas pelayanan adalah faktor penting yang mempengaruhi kepuasan (Carranza,2018) dan pada situasi tertentu kualitas pelayanan tidak menjamin adanya kepuasan pelanggan. Berdasarkan penemuan ini, peneliti telah merumuskan hipotesis sebagai berikut :

Hipotesis 1 (H1) : Kualitas pelayanan berpengaruh terhadap kepuasan pelanggan.

$\mathrm{H}_{0}$ : Tidak ada pengaruh variabel kualitas pelayanan terhadap kepuasan.

$\mathrm{H}_{1}$ : Ada pengaruh variabel kualitas pelayanan terhadap kepuasan.

Dasar pengambilan keputusan dapat dilihat pada nilai $\mathrm{P}$ (probability) yang dihasilkan, yaitu jika $\mathrm{p}>0,05$ maka $\mathrm{H}_{0}$ diterima dan jika $\mathrm{p}<0,05$ maka $\mathrm{H}_{0}$ ditolak.

\section{Hubungan Kepuasan Pelanggan dengan Loyalitas Pelanggan}

Chandra et al (2018), menyatakan bahwa kepuasan pelanggan menyangkut apa yang diungkapkan oleh pelanggan, sedangkan loyalitas pelanggan berkaitan dengan apa yang dilakukan pelanggan. Oleh sebab itu, parameter kepuasan pelanggan lebih subjektif, 
lebih sukar dikuantifikasi, dan lebih sulit diukur daripada loyalitas pelanggan. Salah satu anteseden loyalitas adalah kepuasan. Pendapat yang sama dikemukakan oleh Keshavars et al (2018) yang menyatakan bahwa kepuasan mempunyai asosiasi positif dengan loyalitas. Kepuasan pelanggan harus dibarengi dengan loyalitas pelanggan. Pelanggan yang benarbenar loyal bukan saja sangat potensial menjadi word of mouth advertisers, namun kemungkinan besar juga loyal pada portofolio produk dan jasa perusahaan selama bertahuntahun. Oleh karena itu, hipotesis selanjutnya yang diajukan peneliti adalah :

Hipotesis 2 (H2) : Kepuasan pelanggan berpengaruh terhadap loyalitas pelanggan

$\mathrm{H}_{0}$ : Tidak ada pengaruh variabel kepuasan terhadap loyalitas pelanggan.

$\mathrm{H}_{1}$ : Ada pengaruh variabel kepuasan terhadap loyalitas pelanggan.

Dasar pengambilan keputusan dapat dilihat pada nilai $\mathrm{P}$ (probability) yang dihasilkan, yaitu jika $\mathrm{p}>0,05$ maka $\mathrm{H}_{0}$ diterima dan jika $\mathrm{p}<0,05$ maka $\mathrm{H}_{0}$ ditolak.

Kualitas pelayanan yang baik tentunya sangat mendukung konsumen selaku pengguna jasa untuk lebih loyal dalam menggunakan jasa yang ditawarkan oleh pihak penyedia jasa. Dimana kualitas pelayanan itu sendiri merupakan selisih antara kinerja dan harapan, dimana selisih positif menyebabkan kepuasan pelanggan dan selisih negatif menyebabkan keluhan pelanggan. Apabila pelanggan puas tentunya tingkat loyalitas pelanggan semakin tinggi. Dalam berbagai penelitian dinyatakan bahwa Kualitas Pelayanan memiliki pengaruh positif terhadap loyalitas pelanggan (Carranza et al,2018). Namun berbeda dengan hasil penelitian Chandra et al (2018) yang menyatakan bahwa kualitas pelayanan secara langsung mempunyai pengaruh negatif terhadap loyalitas. Maka dari itu, hipotesis ini diajukan :

Hipotesis $3(\mathbf{H 3})$ : Kualitas pelayanan berpengaruh terhadap loyalitas pelanggan

$\mathrm{H}_{0}$ : Tidak ada pengaruh variabel kualitas pelayanan terhadap loyalitas pelanggan.

$\mathrm{H}_{1}$ : Ada pengaruh variabel kualitas pelayanan terhadap loyalitas pelanggan.

Carranza et al (2018) yaitu Kualitas pelayanan mempunyai hubungan pengaruh terhadap loyalitas melalui kepuasan. Namun berbeda halnya dengan hasil penelitian Chandra et al (2018) yang menyatakan bahwa tidak terdapat sebuah korelasi positif antara kualitas pelayanan dengan loyalitas pelanggan melalui kepuasan pelanggan. Oleh karena itu, hipotesis terakhir yang diajukan oleh peneliti adalah :

Hipotesis $4(\mathbf{H} 4)$ : Kualitas pelayanan berpengaruh terhadap loyalitas pelanggan melalui kepuasan pelanggan

$\mathrm{H}_{0}$ : Tidak ada pengaruh variabel kualitas pelayanan terhadap loyalitas pelanggan dengan kepuasan pelanggan sebagai variabel intervening.

$\mathrm{H}_{1}$ : Ada pengaruh variabel kualitas pelayanan terhadap loyalitas pelanggan dengan kepuasan pelanggan sebagai variabel intervening..

\section{Metode}

Pada penelitian ini menggunakan 3 (tiga) Variabel yaitu : Kualitas Pelayanan (X1), Kepuasan pelanggan (Intervening), Loyalitas (Y). Adapun pola hubungan variabel tersebut dapat digambarkan sebagai berikut : 


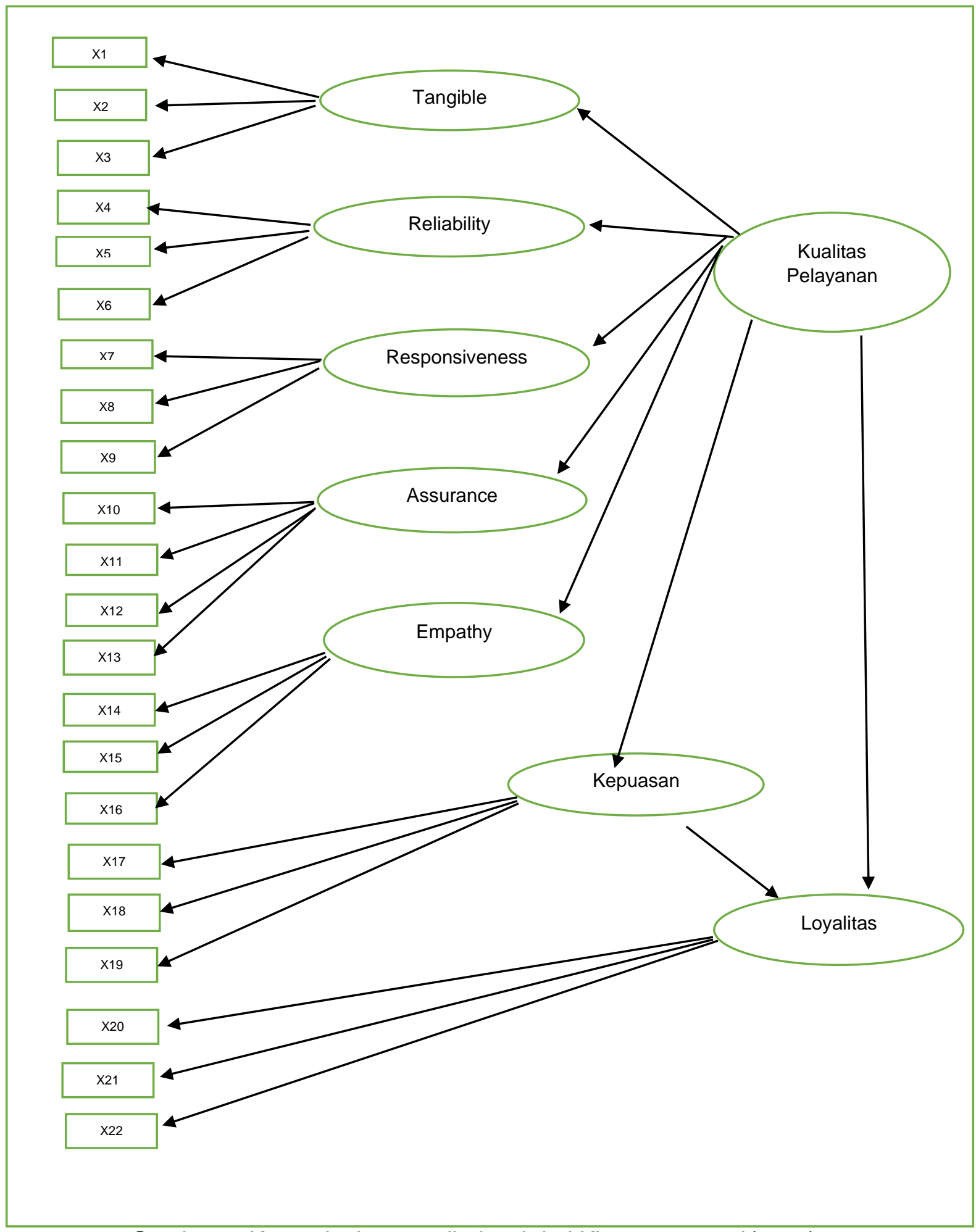

Gambar 1. Kerangka konsep diadopsi dari Khesavars et al (2018)

Kualitas Pelayanan Variabel eksogen dalam penelitian ini adalah Kualitas Pelayanan. Menurut Khesavars et al (2018) dimana kecenderungan konsumen selaku pelanggan melihat kualitas pelayanan terdiri dari 5 (lima) dimensi yaitu Tangibles (bukti fisik), Reliability (kehandalan), Responsiveness (Daya Tanggap), Assurance (jaminan), Empathy (Empati). Dimana indikator-indikator yang digunakan dalam penelitian ini adalah sebagai berikut : 
Tabel 1. Indikator dalam Penelitian

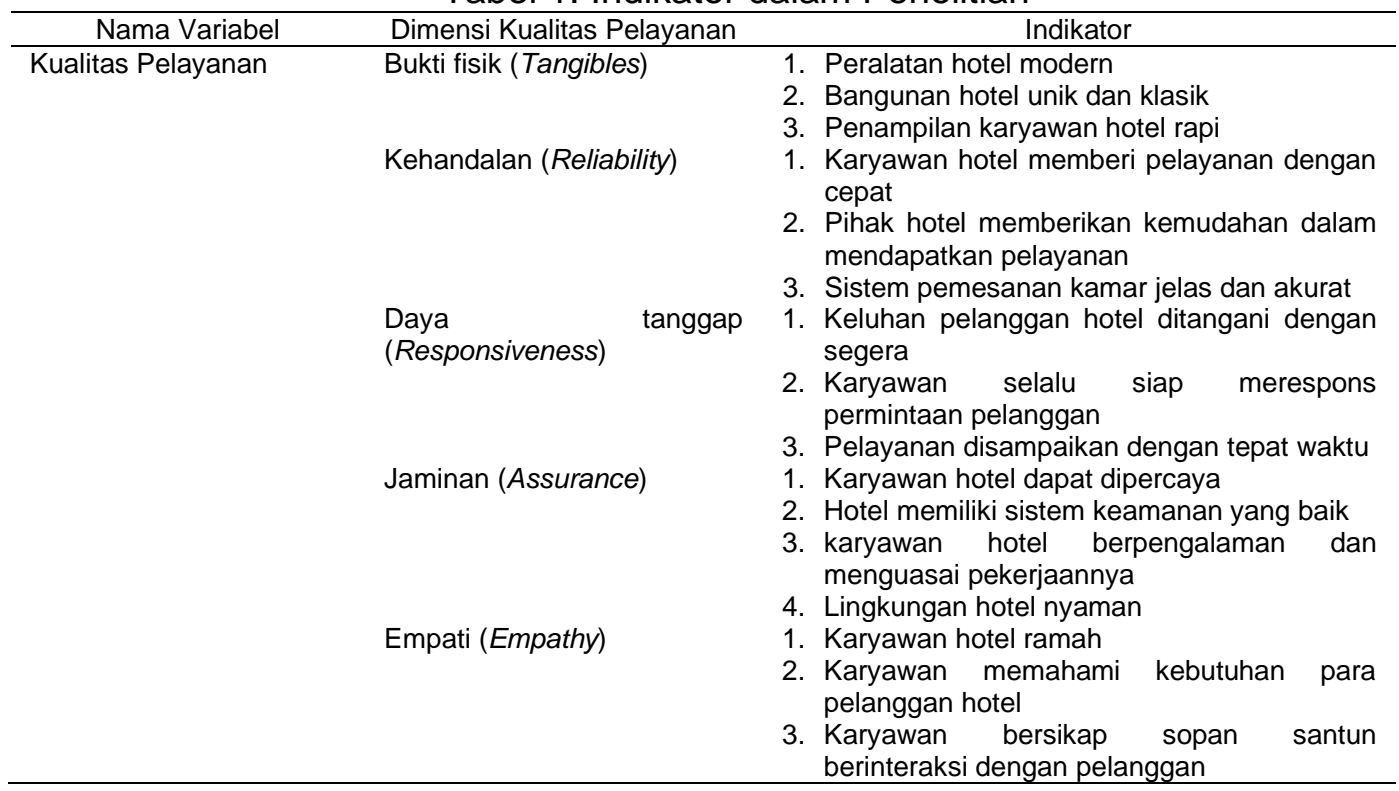

Kepuasan Pelanggan merupakan variabel intervening dalam penelitian ini. Menurut Khesavars et al (2018) menyatakan bahwa kepuasan akan tercapai apabila pelanggan merasakan bahwa harapannya sesuai dengan kenyataan yang ada. Adapun indikatorindikator yang digunakan dalam penelitian ini adalah sebagai berikut :

Tabel 2. Indikator dalam Penelitian

\begin{tabular}{cl}
\hline Nama Variabel & \multicolumn{1}{c}{ Indikator } \\
\hline Kepuasan Pelanggan & Kinerja pelayanan hotel sesuai dengan harapan pelanggan \\
& Fasilitas yang disediakan sesuai dengan harga yang ditawarkan \\
& Secara keseluruhan pelayanan hotel memuaskan pelanggan \\
\hline
\end{tabular}

Loyalitas Pelanggan dalam penelitian ini merupakan variabel endogen (dependen). Pelanggan yang memiliki loyalitas dapat dinilai dari sikap dan perilakunya yang cenderung melakukan pembelian kembali, merekomendasikan produk atau jasa yang digunakan pada orang lain, dan bersedia membayar lebih atas pelayanan yang didapatkan (Khesavars et al, 2018). Maka dari itu, indikator-indikator yang digunakan dalam penelitian ini adalah sebagai berikut :

Tabel 3. Indikator dalam Penelitian

\begin{tabular}{|c|c|}
\hline Nama Variabel & Indikator \\
\hline Loyalitas Pelanggan & $\begin{array}{l}\text { 1. Pelanggan menginap kembali di hotel dalam waktu yang lebih } \\
\text { lama } \\
\text { 2. Pelanggan merekomendasikan hotel kepada teman dan } \\
\text { saudara } \\
\text { 3. Pelanggan bersedia membayar lebih atas produk tambahan } \\
\text { hotel }\end{array}$ \\
\hline
\end{tabular}

Populasi dalam penelitian ini adalah tamu selaku pelanggan yang menginap di Ratu Hotel (Ex.Queen Hotel) Denpasar. Pada penelitian ini, Penetapan jumlah sampel 200 orang telah sesuai dengan kriteria yang ditetapkan oleh Sarjono et al (2019)) yang menyatakan bahwa untuk Model Structural Equation Modeling (SEM) dengan jumlah variabel laten sampai dengan lima buah dan setiap variabel dijelaskan oleh tiga atau lebih indikator, jumlah sampel 100-200 orang sudah dianggap memadai. Sampel diambil dengan teknik purposive sampling, yaitu dengan mengambil responden yang memiliki kriteria tertentu.

Penelitian ini menggunakan data kuantitatif yang merupakan data kualitatif yang diberi skor (skoring). Adapun sumber Data pada penelitian ini yaitu Data primer didapat dari observasi dan kuesioner. 
Adapun pengujian instrumen penelitian adalah sebagai berikut : Reliabilitas adalah suatu angka indeks yang menunjuk pada adanya konsistensi dan stabilitas nilai hasil skala pengukuran tertentu (Sugiyono,2017). Setiap alat pengukur seharusnya memiliki kemampuan untuk memberikan hasil pengukuran yang konsisten. Terdapat banyak teknik untuk mengukur reliabilitas, salah satunya adalah dengan menggunakan Rumus Cronbach's Alpha (ó). Suatu variabel dikatakan reliabel jika memberikan nilai Cronbach's Alpha (ó) > 0,60 .

Uji Validitas menurut Sugiyono (2017), menjelaskan bahwa validitas menunjukkan sejauh mana suatu alat pengukur itu mengukur apa yang ingin diukur. Jika peneliti menggunakan kuesioner dalam pengumpulan data penelitian, maka kuesioner yang disusunnya harus mengukur apa yang ingin diukurnya. Uji validitas digunakan untuk menguji apakah setiap item dalam variabel dapat dimengerti oleh responden sehingga mampu memberikan jawaban yang tepat. Instrumen yang valid berarti alat ukur yang digunakan untuk mengukur tersebut valid. Valid berarti instrumen tersebut dapat digunakan untuk mengukur apa yang seharusnya diukur. Uji Validitas dilakukan dengan pendekatan Product Moment dengan koefisien lebih dari 0,3 sehingga dinyatakan valid.

\section{Hasil dan Pembahasan}

Uraian berikut menjelaskan hasil pengujian yang telah dilakukan, yaitu : Reliabilitas Internal Berkaitan dengan konsistensi dalam pengukuran telah dilakukan pengujian Cronbach's Alpha (ó), dapat dilihat pada tabel berikut ini :

Tabel 4. Hasil Pengujian Reliabilitas Internal

\begin{tabular}{llc}
\hline Nama Variabel & Dimensi & Koefisien reliabilitas \\
\hline Kualitas Pelayanan & Tanggible & 0.919 \\
& Reliability & 0.920 \\
& Responsiveness & 0.922 \\
& Assurance & 0.937 \\
& Emphaty & 0.932 \\
Kepuasan Konsumen & & 0.923 \\
Loyalitas Konsumen & & 0.935 \\
\hline
\end{tabular}

Berdasarkan hasil pengujian tersebut dapat diketahui bahwa masing-masing variabel yang diuji memiliki koefisien reliabilitas (Cronbach's Alpha) melebihi 0,6 dengan demikian instrumen yang digunakan dalam penelitian dinyatakan reliabel.

Hasil pengujian Validitas dengan menggunakan pendekatan Product Moment dapat dilihat pada tabel berikut ini :

Tabel 5. Hasil Pengujian Validitas Internal

\begin{tabular}{crrrrrrr}
\hline Item & \multicolumn{3}{c}{ Kualitas Pelayanan } & \multicolumn{2}{c}{ Pelanggan } \\
\cline { 2 - 7 } & Tangible & Reliability & Responsiveness & Assurance & Empathy & Kepuasan & Loyalitas \\
\hline 1 & 0.859 & 0.834 & 0.831 & 0.816 & 0.866 & 0.852 & 0.876 \\
2 & 0.803 & 0.835 & 0.849 & 0.856 & 0.845 & 0.809 & 0.869 \\
3 & 0.850 & 0.846 & 0.846 & 0.847 & 0.870 & 0.867 & 0.849 \\
4 & & & 0.881 & & & \\
\hline
\end{tabular}

Dilihat dari hasil pengujian validitas internal tersebut, maka Hasil pengujian Product Moment mendapatkan koefesien korelasi sebesar 0.859 pada pertanyaan pertama dimensi tangible, hasil lebih dari 0.3 menandakan pertanyaan memiliki ketepatan dan kecermatan dalam fungsi ukurnya atau valid. Pertanyaan kedua dalam dimensi yang sama mendapatkan koefisien korelasi sebesar 0.803 berarti juga valid, demikian seterusnya semua item memiliki koefesien korelasi lebih dari 0.3 sehingga dinyatakan valid.

Kemampuan manifes dalam merefleksikan laten dievaluasi dengan uji CFA (confirmatory factor analysis). Parameter yang menandakan keberhasilan refleksi adalah koefisien $\lambda$, bila nilainya cukup besar yang ditandai oleh probabilitas ( $p$ ) kurang atau sama dengan 0.05 berarti sukses merefleksikan atau valid.

Kesuksesan manifes dalam tabel 3.3 adalah ketika merefleksikan dimensi-dimensi kualitas pelayanan, tidak merepresentasikan kesuksesan dimensi dalam merefleksikan laten 
kualitas pelayanan. Untuk kemampuan dimensi diperlihatkan dalam tabel 3.3. Terlihat memiliki lambda $(\lambda)$ dengan $p \leq 0.05$, berarti dimensi signifikan sebagai manifes kualitas pelayanan.

\begin{tabular}{lcc}
\multicolumn{2}{c}{ Tabel 6. Hasil Confirmatory Factor Analysis Kualitas Pelayanan } \\
\hline Dimensi & $\lambda$ & $\mathrm{p}$ \\
\hline Tanggible & 0.833 & Ref \\
Reliability & 0.560 & 0.000 \\
Responsiveness & 0.846 & 0.000 \\
Assurance & 0.572 & 0.000 \\
Emphaty & 0.221 & 0.000 \\
\hline
\end{tabular}

Tiga manifes kepuasan pelanggan secara berturut menghasilkan lambda $(\lambda)$ sebesar ; 0.91, 0.85 dan 0.93 , ketiganya memiliki probabilitas 0.000 . Seperti pada variabel sebelumnya, perolehan $p \leq 0.000$ menandakan signifikan sebagai manifes.

\begin{tabular}{lcr}
\multicolumn{4}{c}{ Tabel 7. Hasil Confirmatory Factor Analysis Kepuasan Pelanggan } \\
\hline Manifes & $\lambda$ & $\mathrm{p}$ \\
\hline x17 & 0.909 & Ref \\
x18 & 0.845 & 0.000 \\
19 & 0.929 & 0.000 \\
\hline
\end{tabular}

Laten loyalitas juga sukses direfleksikan oleh manifesnya, informasi ini berdasarkan hasil pengujian yang menghasilkan lambda dengan $p \leq 0.05$. Besarnya lambda dalam Tabel 3.5 menunjukan masing-masing manifes secara berturut sebesar ; 0.93, 0.91 dan 0.89. Ketiganya memiliki probabilitas 0.000 .

Tabel 8. Hasil Confirmatory Factor Analysis Loyalitas Pelanggan

\begin{tabular}{lcr}
\hline Manifes & $\lambda$ & $\mathrm{p}$ \\
\hline $\mathrm{x} 17$ & 0.926 & Ref \\
$\mathrm{x} 18$ & 0.913 & 0.000 \\
$\mathrm{x} 19$ & 0.888 & 0.000 \\
\hline
\end{tabular}

Reliabilitas konstruk dapat dievaluasi berdasarkan koefisien lambda $(\lambda)$ masingmasing manifes dalam laten. Tabel 3.6 dibawah memperlihatkan ringkasan hasil perhitungan yang telah dilakukan, terlihat setiap laten memiliki koefisien reliabilitas konstruk lebih dari 0.6. Berarti semua variabel laten memiliki manifes yang bersifat unidimensi, sehingga tidak perlu dilakukan perubahan atau penggantian manifes.

Tabel 9.Hasil Perhitungan Reliabilitas Konstruk

\begin{tabular}{|c|c|c|c|c|c|c|}
\hline Laten & Manifes & $\lambda$ & e & $\left(\sum \lambda\right)^{2}$ & $\sum \mathrm{e}$ & $\begin{array}{r}\text { konstruk } \\
\text { reliabilitas }\end{array}$ \\
\hline \multirow{5}{*}{ Kualitas Pelayanan } & Tangible & 0.833 & 0.306 & 9.193 & 2.901 & 0.760 \\
\hline & Reliability & 0.560 & 0.686 & & & \\
\hline & Responsiveness & 0.846 & 0.284 & & & \\
\hline & Assurance & 0.572 & 0.673 & & & \\
\hline & Emphaty & 0.221 & 0.951 & & & \\
\hline \multirow{3}{*}{ Tangible } & Tang1 & 0.922 & 0.150 & 7.150 & 0.613 & 0.921 \\
\hline & Tang2 & 0.845 & 0.286 & & & \\
\hline & Tang3 & 0.907 & 0.177 & & & \\
\hline \multirow{3}{*}{ Reliability } & Rel1 & 0.886 & 0.215 & 7.145 & 0.618 & 0.920 \\
\hline & Rel2 & 0.892 & 0.204 & & & \\
\hline & Rel3 & 0.895 & 0.199 & & & \\
\hline \multirow{3}{*}{ Responsiveness } & Res1 & 0.880 & 0.226 & 7.188 & 0.604 & 0.923 \\
\hline & Res2 & 0.900 & 0.190 & & & \\
\hline & Res3 & 0.901 & 0.188 & & & \\
\hline \multirow{4}{*}{ Assurance } & Ass1 & 0.849 & 0.279 & 12.603 & 0.846 & 0.937 \\
\hline & Ass2 & 0.890 & 0.208 & & & \\
\hline & Ass3 & 0.886 & 0.215 & & & \\
\hline & Ass 4 & 0.925 & 0.144 & & & \\
\hline \multirow{3}{*}{ Empathy } & Emp1 & 0.914 & 0.165 & 7.388 & 0.537 & 0.932 \\
\hline & Emp2 & 0.884 & 0.219 & & & \\
\hline & Emp3 & 0.920 & 0.154 & & & \\
\hline Kepuasan Pelangqan & Kp1 & 0.909 & 0.174 & 7.198 & 0.597 & 0.923 \\
\hline
\end{tabular}




\begin{tabular}{clrrrrr}
\hline Laten & Manifes & $\lambda$ & $\mathrm{e}$ & $\left(\sum \lambda\right)^{2}$ & $\sum \mathrm{e}$ & $\begin{array}{r}\text { konstruk } \\
\text { reliabilitas }\end{array}$ \\
\hline \multirow{6}{*}{ Loyalitas Pelanggan } & Kp2 & 0.845 & 0.286 & & & \\
& Kp3 & 0.929 & 0.137 & & & 0.935 \\
& LP1 & 0.926 & 0.143 & 7.437 & 0.520 & \\
\hline
\end{tabular}

Pengujian distribusi data dilakukan dengan uji skewness dan kurtosis, hasilnya tidak menemukan variabel memiliki nilai critical ratio (CR) kurtosis lebih dari \pm 2.58 (tabel 3.7), hal ini mengindikasikan ketinggian kurva normal yang proporsional (tidak kurus), dan pada CR skewness semuanya kurang dari \pm 2.58 , berarti memiliki kesimetrisan yang baik (tidak juling). Berdasarkan keduanya distribusi data dinyatakan normal.

Tabel 10. Hasil Pengujian Normalitas

\begin{tabular}{|c|c|c|c|c|c|c|}
\hline No & Laten & Manifest & Skewwnes & CR & Kurtosis & \\
\hline \multirow[t]{4}{*}{1} & Tangible & & & & & \\
\hline & & $x 1$ & -0.321 & -1.852 & -0.782 & -2.256 \\
\hline & & $x 2$ & -0.316 & -1.826 & -0.730 & -2.108 \\
\hline & & $x 3$ & -0.287 & -1.655 & -0.707 & -2.041 \\
\hline \multirow[t]{3}{*}{2} & Reliability & $x 4$ & -0.391 & -2.257 & -0.655 & -1.892 \\
\hline & & x5 & -0.377 & -2.177 & -0.768 & -2.216 \\
\hline & & $x 6$ & -0.347 & -2.003 & -0.706 & -2.039 \\
\hline \multirow[t]{3}{*}{3} & Responsiveness & $x 7$ & -0.369 & -2.132 & -0.774 & -2.233 \\
\hline & & $x 8$ & -0.380 & -2.193 & -0.737 & -2.129 \\
\hline & & $x 9$ & -0.379 & -2.188 & -0.774 & -2.235 \\
\hline \multirow[t]{4}{*}{4} & Assurance & $\mathrm{x} 10$ & -0.239 & -1.378 & -0.738 & -2.131 \\
\hline & & $\mathrm{x} 11$ & -0.356 & -2.053 & -0.618 & -1.785 \\
\hline & & $\mathrm{x} 12$ & -0.317 & -1.827 & -0.737 & -2.127 \\
\hline & & $\mathrm{x} 13$ & -0.336 & -1.942 & -0.695 & -2.006 \\
\hline \multirow[t]{3}{*}{5} & Empathy & $\mathrm{x} 14$ & -0.337 & -1.945 & -0.693 & -2.001 \\
\hline & & $\mathrm{x} 15$ & -0.356 & -2.054 & -0.769 & -2.220 \\
\hline & & $\mathrm{x} 16$ & -0.321 & -1.853 & -0.799 & -2.307 \\
\hline \multirow[t]{3}{*}{6} & Kepuasan pelanggan & $\mathrm{x} 17$ & -0.250 & -1.441 & -0.794 & -2.292 \\
\hline & & $\mathrm{x} 18$ & -0.295 & -1.703 & -0.693 & -2.002 \\
\hline & & $\mathrm{x} 19$ & -0.267 & -1.544 & -0.771 & -2.225 \\
\hline \multirow[t]{3}{*}{7} & Loyalitas pelanggan & $x 20$ & -0.379 & -2.189 & -0.654 & -1.887 \\
\hline & & $x 21$ & -0.379 & -2.190 & -0.741 & -2.139 \\
\hline & & $\times 22$ & -0.338 & -1.950 & -0.688 & -1.987 \\
\hline
\end{tabular}

Outlier menjelaskan keberadaan subjek yang memiliki skor sangat berbeda dari reratanya. Parameter penanda keberadaan outlier adalah Mahalanobis distance yang melebihi chi square tabel $89.272(\mathrm{df}=52, \alpha \square=0.001)$, dalam tabel 3.8 di bawah tidak ditemukan nilai mahalanobis yang nilainya melebihi sehingga dinyatakan tidak ada data yang terlalu ekstrim atau outlier.

Tabel 11. Mahalanobis Terbesar

\begin{tabular}{cll}
\hline $\begin{array}{l}\text { No } \\
\text { Kasus }\end{array}$ & Kuadrat Mahalanobis & $\begin{array}{l}\text { Chi Square Tabel } \\
\text { (df }=52, \alpha \square=0.001)\end{array}$ \\
\hline 177 & 65.319 & 89.272 \\
7 & 63.663 & 89.272 \\
82 & 61.780 & 89.272 \\
54 & 52.752 & 89.272 \\
95 & 47.594 & 89.272 \\
\hline
\end{tabular}

Kesesuaian model mengevaluasi kecocokan antara kovarian sampel dengan populasi, bila hasilnya sesuai berarti model mendapat dukungan secara empiris sehingga tidak diperlukan perubahan atau modifikasi. Sebaliknya berarti perlu dilakukan modifikasi. Salah satu penanda yang menunjukkan kecocokan ini adalah Koefesien Chi Square. Dari hasil pengujian diperoleh koefesien chi square sebesar 400.390 dengan probabilitas (p) sebesar 0.000 , perolehan $p<0.05$ menunjukkan ada perbedaan signifikan antara kovarian sampel dengan populasi sehingga model dinyatakan kurang kurang cocok. Chi Square adalah absolute fit indeks, sehingga cukup menjadi dasar untuk melakukan modifikasi model. 
Tabel 12. Hasil Goodness of Fit Index Model Sebelum Perubahan

\begin{tabular}{lllll}
\hline No & Index & Cut of Value & Hasil & Keterangan \\
\hline 1 & Kai Kuadrat & Kecil & 790.390 & \\
& $(\mathrm{p})$ & $(\mathrm{p}>0.05)$ & $(\mathrm{p}=0.000)$ & Tidak Terpenuhi \\
2 & CFI & $\geq 0.90(\max 1)$ & 0.949 & Terpenuhi \\
3 & GFI & $\geq 0.95(\max 1)$ & 0.849 & Moderat \\
4 & AGFI & $\geq 0.95(\max 1)$ & 0.809 & Moderat \\
5 & RMSEA & $\leq 0.08(\operatorname{Min} 0)$ & 0.071 & Terpenuhi \\
6 & TLI & $\geq 0,95(\max 1)$ & 0.942 & Moderat \\
\hline
\end{tabular}

Secara struktural tidak dilakukan perubahan terhadap variabel utama yang dihipotesakan, perubahan hanya pada variabel error dari variabel laten kualitas pelayanan dan kepuasan. Hal ini wajar terjadi karena pada dasarnya memiliki kesamaan dimensi yang bisa menguat sewaktu-waktu. Fenomena yang sama juga terjadi pada laten kepuasan dan loyalitas. Nilai chi square setelah model mengalami perubahan menjadi 638.126 dengan probabilitas (p) sebesar 0.083 , perubahan probabilitas (p) menjadi lebih dari 0.05 menunjukan telah terjadi perbaikan penerimaan model. Tidak lagi terjadi perbedaan signifikan antara kovarian sampel dengan kovarian yang estmasi, berarti model yang diajukan mendapat dukungan kuat dari sampel untuk menjelaskan estimasi atau populasi.

Tabel 13. Hasil Goodness of Fit Index Model Setelah Perubahan

\begin{tabular}{lllll}
\hline No & Index & Cut of Value & Hasil & Keterangan \\
\hline 1 & Kai Kuadrat & Kecil & 222.107 & \\
& $(p)$ & $(p>0.05)$ & $(p=0.097)$ & Terpenuhi \\
2 & CFI & $\geq 0.90(\max 1)$ & 0.993 & Terpenuhi \\
3 & GFI & $\geq 0.95(\max 1)$ & 0.910 & Moderat \\
4 & AGFI & $\geq 0.95(\max 1)$ & 0.8854 & Moderat \\
5 & RMSEA & $\leq 0.08(\min 0)$ & 0.026 & Terpenuhi \\
6 & TLI & $\geq 0,95(\max 1)$ & 0.992 & Terpenuhi \\
\hline
\end{tabular}

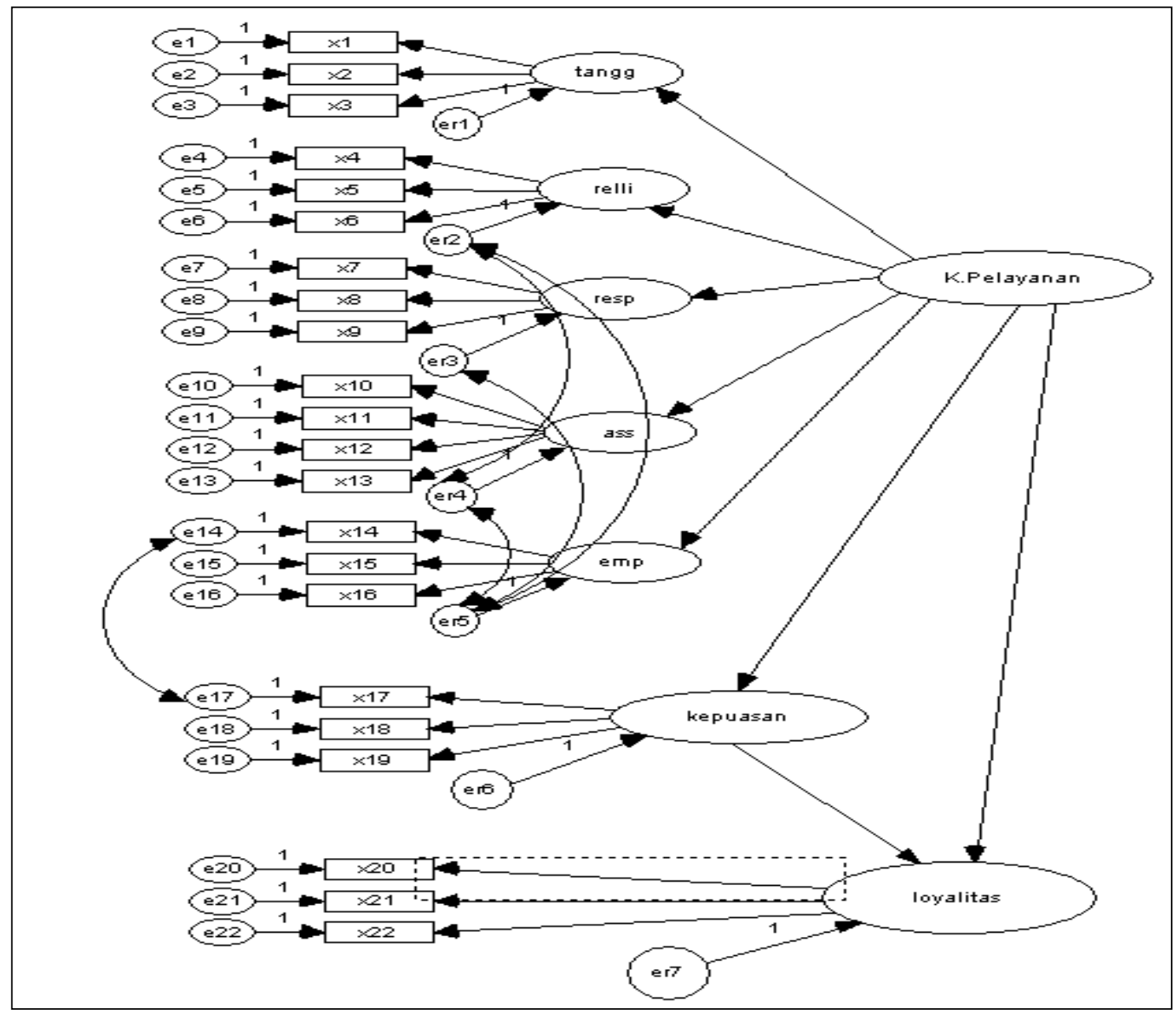

Gambar 2. Model Setelah Perubahan 
Tabel 14. Hasil Pengujian Struktural

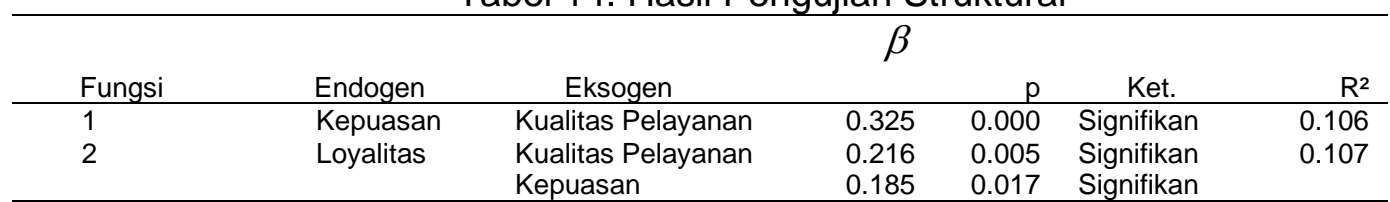

Fungsi kedua secara matematis dapat dituliskan, yaitu : Loyalitas $=0.216$ kualitas pelayanan +0.185 kepuasan, fungsi ini menjelaskan bahwa loyalitas pelanggan Ratu Hotel dapat dijelaskan oleh kualitas pelayanan yang diberikan perusahaan dan kepuasan yang diterima pelanggan. Secara bersama keduanya dapat menjelaskan loyalitas pelanggan sampai $10.7 \%$, sisanya sebesar $89.7 \%$ dijelaskan oleh variabel lain.

Dalam fungsi loyalitas tersebut variabel kualitas pelayanan dan kepuasan pengaruhnya signifikan, hal ini ditunjukan oleh nilai $p \leq 0.05$, yaitu 0.000 dan 0.005 serta 0.017. Adanya pengaruh signifikan ini merupakan fakta empiris yang mendukung hipotesis pertama : Kualitas pelayanan berpengaruh terhadap kepuasan pelanggan, hipotesis kedua; Kepuasan Pelanggan berpengaruh terhadap loyalitas pelanggan, hipotesis ketiga ; Kualitas pelayanan berpengaruh terhadap loyalitas pelanggan. Dua dukungan empiris ini menjadi dasar untuk menyatakan bahwa hipotesis terbukti. Dalam intervening tersebut, kualitas pelayanan secara langsung mampu menjelaskan loyalitas pelanggan Ratu Hotel sebesar 0.216 atau $4.67 \%$, dan secara tidak langsung melalui kepuasan sebesar 0.060 atau $0.36 \%$.

Industri perhotelan di Bali pada saat ini telah menjadi industri yang memasuki tahap "mature", dimana terjadi persaingan ketat dalam memperoleh pelanggan. Kondisi ini ditandai dengan munculnya berbagai bentuk usaha di bidang perhotelan. Jumlah kamar yang tersedia jauh di atas jumlah permintaan konsumen selaku pelanggan. Usaha untuk meyakinkan konsumen agar mau menjadi pelanggan Ratu Hotel (Ex.Queen Hotel) adalah hal yang tidak mudah, terutama bagi mereka yang belum pernah mengenal hotel ini sebelumnya. Salah satu strategi yang efektif dalam pemasaran hotel adalah melalui loyalitas tamu selaku pelanggan. Tamu yang loyal bukan hanya sekedar tamu, tetapi dapat menjadi bagian integral dalam pemasaran hotel. Memelihara tamu selaku pelanggan yang ada lebih mudah daripada meyakinkan calon tamu yang baru untuk datang dan menginap di hotel.

Adapun hasil pembahasan mengenai kualitas pelayanan yang terdiri dari 5 (lima) dimensi adalah sebagai berikut :

Tabel 15 Pembahasan Mengenai Kualitas Pelayanan

\begin{tabular}{lccc}
\hline \multicolumn{1}{c}{ Keterangan } & $\begin{array}{c}\text { Uji second orders } \\
\text { CFA }\end{array}$ & $\begin{array}{c}\text { Nilai squared multiple } \\
\text { correlation }\end{array}$ & $\begin{array}{c}\text { Hasil rerata } \\
\text { tertimbang }\end{array}$ \\
\hline a. Bukti fisik & $0,833 / 83 \%$ & $0,694 / 69 \%$ & 3,402 \\
b. Kehandalan & $0,560 / 56 \%$ & $0,314 / 31 \%$ & 3,387 \\
c. Daya tanggap & $0,846 / 85 \%$ & $0,846 / 85 \%$ & 3,407 \\
d. Jaminan & $0,572 / 57 \%$ & $0,327 / 33 \%$ & 3,369 \\
e. Empati & $0,221 / 22 \%$ & $0,049 / 5 \%$ & 3,400 \\
\hline
\end{tabular}

Penjelasannya adalah sebagai berikut : Hasil Uji second orders membuktikan bahwa 5 (lima) dimensi ini memiliki pengaruh positif dan signifikan terhadap kualitas pelayanan dengan persentase masing-masing $83 \%, 56 \%, 85 \%, 57 \%, 22 \%$. Nilai squared multiple correlation menjelaskan bahwa 5 (lima) dimensi tersebut menjelaskan variabel kualitas pelayanan sebesar $69 \%, 31 \%, 85 \%, 33 \%, 5 \%$ dan selebihnya dijelaskan oleh unique faktor yang lain. Hasil rerata tertimbang membuktikan bahwa 5(lima) dimensi ini menunjukkan penilaian responden terhadap kualitas pelayanan yang diberikan melebihi moderat, berarti dapat menerima dengan baik pelayanan yang diberikan oleh Ratu Hotel, dengan nilai rerata masing-masing yaitu 3,402, 3,387, 3,407, 3,369, 3,400.

Adapun hasil pembahasan mengenai kepuasan pelanggan adalah sebagai berikut : pada kepuasan pelanggan (Tabel 3.12) Pengukuran terhadap tingkat kepuasan pelanggan Ratu Hotel mendapatkan skor rata-rata sebesar 3.292, besaran lebih dari 3 menunjukan lebih dari moderat dalam skala $1-5$. Sehingga dapat dijelaskan bahwa pelanggan Ratu 
Hotel relatif puas dengan jasa yang diberikan, fakta ini mengisyaratkan kesuksesan hotel dalam memberikan pelayanan yang sesuai dengan harapan pelanggan meskipun belum tepat sekali, dimana yang menjadi penyebabnya adalah karena masih terdapat beberapa harapan dari pelanggan yang belum sepenuhnya dapat diberikan oleh karyawan Ratu Hotel

dalam memberikan pelayanan. Adapun Hasil perhitungan statistik deskriptif mengenai loyalitas pelanggan yaitu mendapatkan skor rata-rata sebesar 3.242, merupakan skor yang cukup tinggi dalam skala pengukuran $1-5$. Berarti ada harapan yang cukup besar pelanggan akan tetap mengggunakan jasa Ratu Hotel (Ex.Queen Hotel) Denpasar-Bali.

\section{Simpulan dan Saran}

Melalui analisis data dan pembahasan hasil analisis data yang telah dilaksanakan pada penelitian ini, dapat dirumuskan beberapa hal sebagai kesimpulan penelitian, yaitu: Kualitas pelayanan berpengaruh positif dan signifikan terhadap kepuasan pelanggan. Hal ini mendukung hasil penelitian Khesavars et al (2018). Kepuasan pelanggan berpengaruh signifikan terhadap loyalitas pelanggan. Hal ini mendukung hasil penelitian Chandra et al (2018). Kualitas pelayanan berpengaruh signifikan terhadap loyalitas pelanggan. Hal ini mendukung hasil penelitian (Carranza et al, 2018). Kualitas pelayanan berpengaruh signifikan terhadap loyalitas pelanggan dengan kepuasan pelanggan sebagai variabel intervening. Penemuan pada penelitian ini juga didukung oleh hasil penelitian terdahulu yaitu : Carranza et al (2018). Hal ini berarti bahwa adanya pelayanan yang baik dari karyawan Ratu Hotel (Ex.Queen Hotel) menyebabkan pelanggan semakin puas karena harapannya sesuai dengan kenyataan, dimana semakin puas pelanggan terhadap pelayanan yang diperolehnya, maka pelanggan akan semakin loyal untuk menggunakan kembali jasa Ratu Hotel (Ex.Queen Hotel) Denpasar-Bali.

Berdasarkan atas hasil penelitian ini, diajukan beberapa saran sebagai berikut: Dalam penelitian ini telah dibuktikan bahwa loyalitas pelanggan Ratu Hotel (Ex.Queen Hotel) Denpasar-Bali dipengaruhi secara positif dan signifikan oleh kualitas pelayanan dan kepuasan pelanggan. Oleh karena itu pihak hotel perlu memperhatikan kualitas pelayanan hotel dan kepuasan pelanggan sebagai tamu hotel. Kualitas pelayanan yang dimaksudkan adalah pelayanan yang memperhatikan faktor fisik hotel, daya tanggap, jaminan, dan empati yang telah terbukti secara signifikan merupakan faktor yang membentuk kualitas pelayanan Ratu Hotel (Ex.Queen Hotel) Denpasar, sehingga kepuasan mereka dapat tercapai dan berdampak pada loyalitas pelanggan itu sendiri. Pada hasil penelitian ini, dimensi kualitas pelayanan yang terdiri dari Bukti fisik (tangible), Kehandalan (Reliability), Daya tanggap (Responsiveness), Jaminan (Assurance), Empati (Empathy), secara keseluruhan mendapatkan penilaian cukup tinggi berada pada skor melebihi 3, akan tetapi masih dibawah skala 4. hal tersebut berarti kualitas pelayanan Ratu Hotel dianggap oleh responden selaku pelanggan belum terlalu maksimal akan tetapi masih bisa diterima oleh pelanggan. Oleh karena itu penelitian ini dapat dijadikan acuan untuk lebih meningkatkan kualitas pelayanan yang ada sehingga Ratu Hotel (Ex.Queen Hotel) dapat mempertahankan dan bahkan dapat menambah pelanggan yang ada.

Berdasarkan hasil penelitian, dimensi kualitas pelayanan yaitu empati mendapatkan penilaian yang paling rendah yaitu dengan $\lambda=0,221$ dengan sisanya $95,1 \%$ dijelaskan oleh unique factor (error). Hal ini dapat dijadikan acuan oleh peneliti selanjutnya untuk lebih memperhatikan dan meneliti kembali faktor empati dalam penelitian selanjutnya yang berkaitan dengan kualitas pelayanan. Penelitian serupa dapat pula dilakukan pada jenis usaha jasa lainnya di bidang pariwisata, seperti hotel, butik, restoran, bar, spa atau menggunakan obyek penelitian yang berbeda. Pada penelitian selanjutnya tentang pengaruh kualitas pelayanan, kepuasan pelanggan, dan loyalitas pelanggan pada usaha jasa perhotelan sebaiknya memperhatikan faktor harga untuk dapat dianalisis, karena saat ini begitu banyaknya pesaing yaitu : hotel-hotel baru yang bermunculan dekat dengan lokasi Ratu Hotel (Ex.Queen Hotel). Perkembangan kualitas pelayanan dalam perhotelan sangat berkembang pesat saat ini, sehingga hampir semua hotel sekarang sudah mampu memberikan kualitas pelayanan yang sama baiknya. Kemajuan ini memungkinkan kesimpulan di atas juga berlaku di hotel lain, maka harus diperhatikan lagi bagaimana 
kualitas pelayanan dan kepuasan harus dibangun agar memiliki diferensiasi dengan hotel lain. Adanya diferensiasi ini dapat mengantarkan Ratu Hotel pada kekhasan positif tertentu yang tidak ditemukan di Hotel lain. Diharapkan dengan adanya pelayanan khas yang diberikan Ratu Hotel maka loyalitas lebih dapat ditingkatkan, atau minimal akan membangun komunitas Ratu Hotel (Ex.Queen Hotel) yang kuat.

\section{Daftar Pustaka}

Achchuthan Sivapalan, Charles Jebarajakirthy, (2017) "An application of retailing service quality practices influencing customer loyalty toward retailers", Marketing Intelligence \& Planning, Vol. 35 Issue: 7, pp.842-857, https://doi.org/10.1108/MIP-09-2016-0178

Hung-Che Wu. 2017. What drives experiential loyalty? A case study of Starbucks coffee chain in Taiwan. British Food Journal, Vol. 119 Issue: 3, pp.468-496, https://doi.org/10.1108/BFJ-08-2016-0349

Hung-Che Wu, Ching-Chan Cheng, Yi-Chang Chen, Wien Hong. 2017. Towards green experiential loyalty: driving from experiential quality, green relationship quality, environmental friendliness, green support and green desire. International Journal of Contemporary Hospitality Management, https://doi.org/10.1108//JCHM-10-2016-0596

https://disparda.baliprov.go.id/ , diakses tanggal 20 November 2019

Osaretin Kayode Omoregie, John Agyekum Addae, Stanley Coffie, George Oppong Appiagyei

Ampong, Kwame Simpe Ofori, (2019) "Factors influencing consumer loyalty: evidence from the Ghanaian retail banking industry", International Journal of Bank Marketing, https://doi.org/10.1108/IJBM-04-2018-0099

Rami Mohammad Al-dweeri, Antonia Ruiz Moreno, Francisco Javier Llorens Montes, Zaid Mohammad Obeidat, Khaldoon M. Al-dwairi, (2018) "The effect of e-service quality on Jordanian student's e-loyalty: an empirical study in online retailing", Industrial Management \& Data Systems, https://doi.org/10.1108/IMDS-12-2017-0598

Rocío Carranza, Estrella Díaz, David Martín-Consuegra, (2018) "The influence of quality on satisfaction and customer loyalty with an importance-performance map analysis: Exploring the

mediating role of trust", Journal of Hospitality and Tourism Technology, https://doi.org/10.1108/JHTT-09-2017-0104

Sarjono Haryadi, Julianita winda. 2019. Structural Equation Modelling (SEM). Penerbit : Salemba Empat. Jakarta.

Sugiyono . 2017. Metode Penelitian : Kuantitatif . Kualitatif dan R\&D(a) Bandung : Alfabeta.

Teddy Chandra, Layla Hafni, Stefani Chandra, Astri Ayu Purwati, Jennifer Chandra, (2019) "The influence of service quality, university image on student satisfaction and student loyalty",Benchmarking: An International Journal, https://doi.org/10.1108/BIJ-07-20180212

Yousef Keshavarz, Dariyoush Jamshidi, (2018) "Service quality evaluation and the mediating role of perceived value and customer satisfaction in customer loyalty", International Journal of Tourism Cities, Vol. 4 Issue: 2, pp.220-244, https://doi.org/10.1108/IJTC09-2017-0044 